\title{
The Influence of Leadership Styles on the Effectiveness of the Public Policy Implementation Process in Ethiopia: The Case of Addis Ababa City Government
}

\author{
Mulat Abebel Reta \\ African Leadership Excellence Academy, Addis Ababa, Ethiopia \\ Email address: \\ mulatabebe112@gmail.com \\ To cite this article: \\ Mulat Abebel Reta. The Influence of Leadership Styles on the Effectiveness of the Public Policy Implementation Process in Ethiopia: The \\ Case of Addis Ababa City Government. American Journal of Management Science and Engineering. Vol. 6, No. 5, 2021, pp. 142-160. \\ doi: 10.11648/j.ajmse.20210605.12
}

Received: August 21, 2021; Accepted: September 3, 2021; Published: October 30, 2021

\begin{abstract}
Policy implementation desires the increased commitment and coordination of applicable stakeholders or actors. Policy implementation gap also emanates from leadership development practice because; leadership development and an appointment done through political appointments, rather than career posts depend on the leader's competencies. This study tried to investigate the relationship between specific leadership styles and the effectiveness of the policy implementation process. It is justifiable to conduct this study to contribute and cover the gap in relation to leadership style and policy implementation. This study aimed to explore the influence of leaders' leadership styles on the effectiveness of the policy implementation process in selected government public sectors in Addis Ababa City Government. The study was focused on well know leadership styles i.e., transformational, transactional, and laissez-faire, and the major variables that measure the implementation process effectiveness of policies i.e., policy-practice alignment, stakeholder engagement, active implementation or communication, ongoing evaluation and support, and transparency. The study was employed a descriptive survey design that uses a cross-sectional survey methodology. Primary data were collected from 237 individuals through closed ended questionnaire. The sample was selected using a simple random sampling method. The data analyzed by descriptive statistics (percentages, mean, and standard deviation) and inferential statistics (Pearson Product Moment correlation and multiple regressions). Predominantly the results of the study indicate the transformational leadership style was positively and significantly influences policy implementation process effectiveness ( $\operatorname{sig}=0.000$ at $\mathrm{p}<0.05$ ). Both transactional $(\operatorname{sig}=0.105$ at $\mathrm{p}<0.05$ ) and Laissez-Faire (sig .957 at $\mathrm{p}<0.05$ ) Leadership Style have no statistically significance influence on implementation process effectiveness of policies. Surprisingly, the Laissez-Faire Leadership Style has a statistically insignificant negative influence on the policy implementation process. The study concludes that, if leaders exhibited a transformational leadership style, they could contribute more to the effectiveness of the policy implementation process than transactional and Laissez-Faire Style. It implies that leadership is responsible for the implementation of policies. The study mainly recommends leaders of government public sectors of Addis Ababa City Government to give due emphasis to appropriate leadership style as context as.
\end{abstract}

Keywords: Transformational, Transactional and Laissez-faire Leadership, Policy Implementation

\section{Introduction}

In the contemporary world, different individuals appointed to carry the role and responsibilities of leadership through formulating and implementing policies that include rules, regulations, strategies, and programs. Operationally, leadership has significant role that the organization to reaches its purposes.
Effective policy implementation needs strong leadership. High-level actors and influential leaders can communicate about the policy's goals, rationale, and mechanisms, and champion the policy to ensure implementation, which requires coordination and cooperation. The level of consensus among leaders and 
other policy stakeholders on the content of a policy and its need for implementation will affect the degree and timing. Implementation will likely be the responsibility of local administrators and organizations particularly in the context of decentralization [1]. Therefore, effective leadership is integral to the achievement of the goals and objectives of the organization [2].

Akinboye also argued effective leaders play their role by creating prevailing vision and mission, communicating the vision and mission, clarifying mission and organizational objectives to all levels of the organizations, and steer organizations to high performing outcomes. Leadership and implementing policies have a relationship that the execution and practice of each process have far-reaching implications on others upon which the attainment of goals. As [3], public leadership and public governance are pillars of public policy implementation and foster effective public leadership that results in the successful implementation of public policies. In this global competitive environment, an effective leadership style is necessary to reduce the organizational ineffectiveness and make it possible to achieve organizational goal efficient [4].

For instance, [5] state because of globalization, the process of implementing a policy is complex and it requires an interactive process and influenced by the diverse nature of socio-political and other environmental forces. These environmental forces form quite different policy contexts that in turn lead to the variation in policies and influence the outputs and impacts of those particular policies. They infer due to such contextual disparities significantly affected the effectiveness of implementation process of policies, leadership practices become fluctuated, and instable because of changing circumstances of the society, world, and the organization in particular [6].

It is quite clear that policies are not self-implementing [7]. Administrations in different layers of government are trusted with much greater responsibilities than ever before to deliver services to their residents. Moreover, in their powers and duties, necessary legal, administrative, human, and material requisites have put in place [8]. Doing this needs a public policy that guides to action the broader framework that involves putting into operation a vision and decision that are translated into various programs, projects, and activities. A policy entails or needs the broad statement of future goals and actions, and expresses the means of attaining goals through implementation [9]. Policy implementation requests translating the goals and objectives of policy into action and it is an integral part of the policy cycle [10].

Anderson and James further describe policy implementation necessitate the provision of institutional resources for putting the program into practice under a given bureaucracy or institution. Implementation involves money to spent, laws to be enforced, employees to hire, and action plans to put in place [5]. Policies are not useful if the implementation process is not efficient. Proper implementation of a policy occurs when the conditions and objectives of the policy are satisfied. Researchers suggest that policy implementation is a stage at which problems are going to identify alternatives that examined and legitimated through the adoption of legislation [11].

As per [12] if a policy effectively implemented, the designed and planned development goals, and objectives become reality. However, there is no definitive theory/model of policy implementation effectiveness and very few frameworks have found acceptable as the basis to measure the effectiveness of policy implementation process $[5,13,14]$. The effectiveness of policy implementation can measure by using different indicators. Among the indicators are collaborative, interactive, and entrepreneurial competencies [15] are the common ones. Besides, [16] stated that the effectiveness of policy implementation could be indicated by practice policy alignment, stakeholder engagement, active communication, and ongoing evaluation, and support, transparency throughout the process. Hence, this study was adopted the Stonemeier et al and Fadel indicators to measure the effectiveness of the policy implementation process.

In Ethiopia, internal and external policy environments affect positively or negatively the effectiveness of the policy implementation process. Leadership practices become fluctuated and instable because of changing circumstances of the society, world, and the organization in particular [6]. Thus, it leads to the policy implementation process ineffective. To solve such problems and take to guarantee of internal and external context of policy the government of a country devised strategies like establishing an executing body; creating awareness; capacity building; encouraging employee participation; managing service delivery improvement through research and planning; establishing a national civil service award system; rewarding exemplary performers, and working in partnership with the public. The Federal Government expressed its commitment to the implementation of the Policy in all civil service institutions [17].

To implement the aforementioned policy instruments for the realization of the objectives of the Policy on a sustainable basis, the country also tries to develop leadership academies and centers of policy research institutions. These organizations try to enhance the leader's skill of leadership and the policy implementations easy and effective throughout the country including Addis Ababa city government. Therefore, the very central point of this study was to investigate the relationship of leaders' leadership style and the effectiveness of policy implementation process and further it was identified the appropriate leadership style to the current context of Addis Ababa city government public sectors. The background of the study summarized as: 


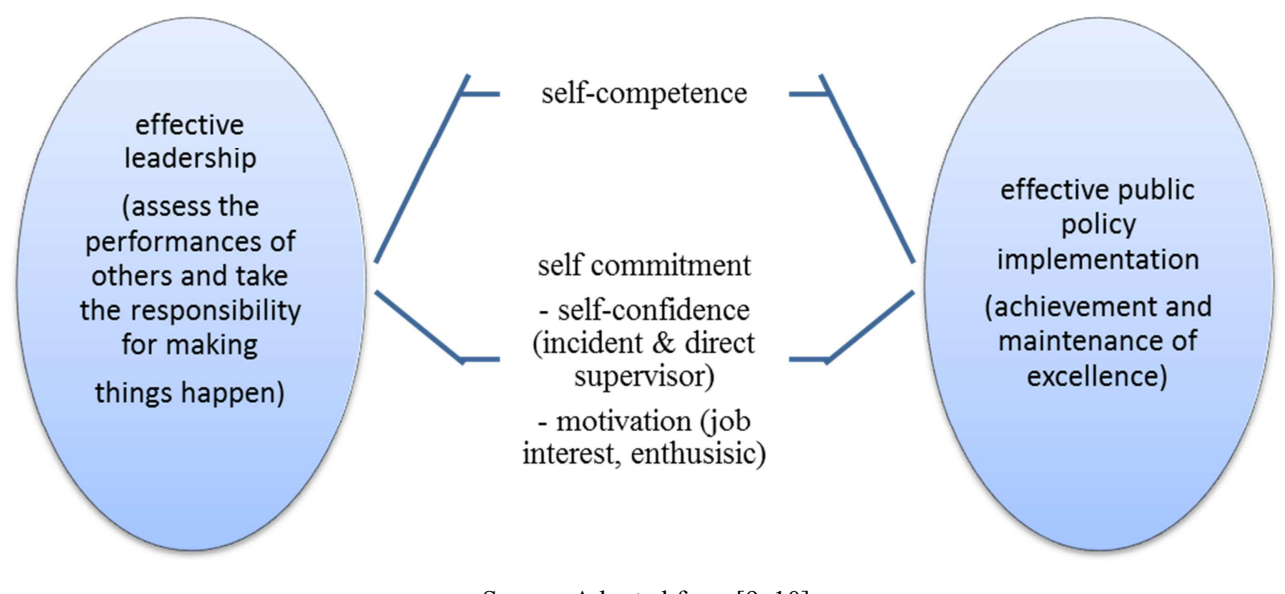

Source: Adopted from [9, 10]

Figure 1. Relationship between leadership and policy implementation.

The hypothesized relationship between leadership styles and policy implementation effectiveness shown as:

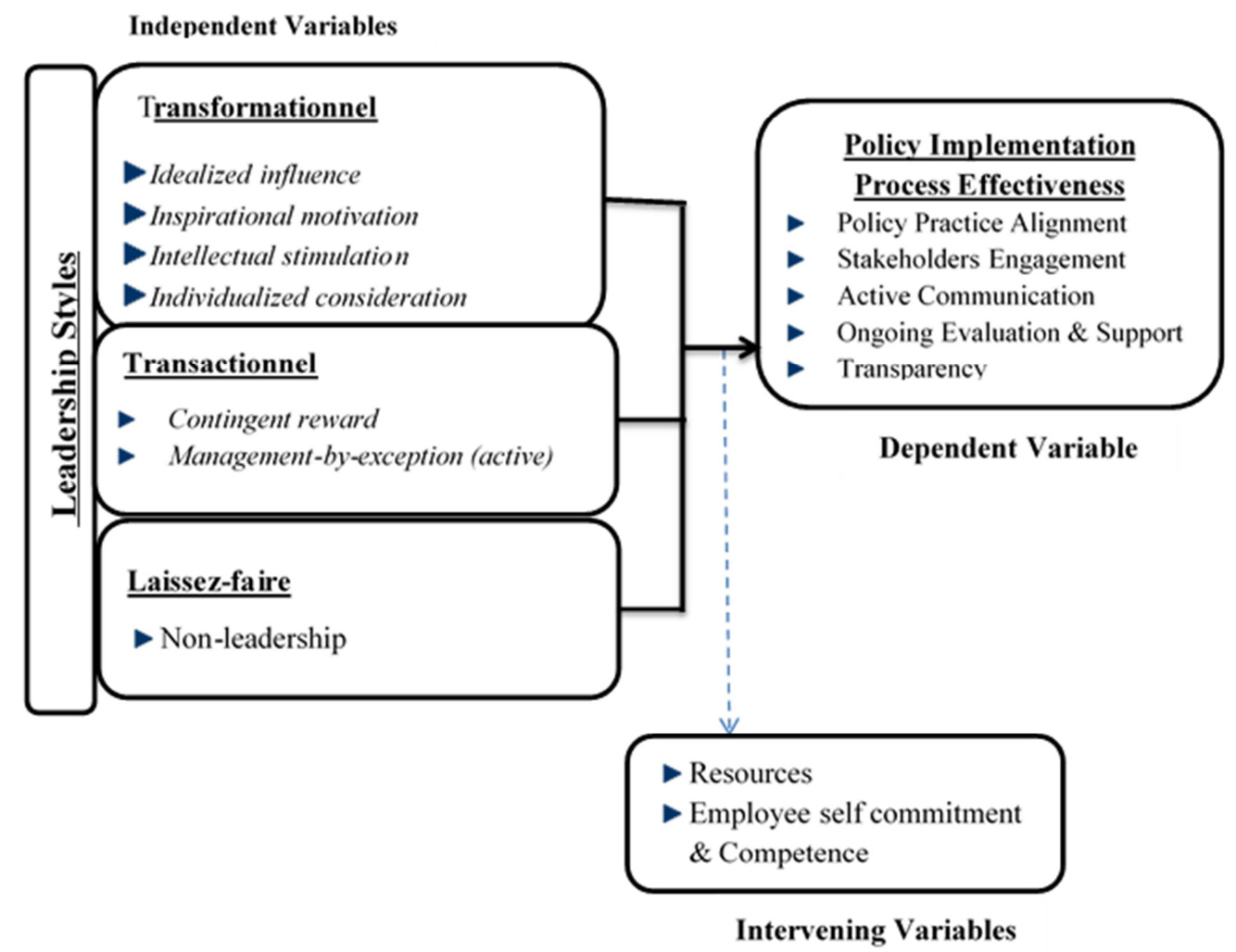

Source: Adopted from [18, 19] models

Figure 2. Conceptual Framework of the Study.

\subsection{Statement of the Problem}

Policy implementation desires increased commitment and coordination of applicable stakeholders or actors. In Ethiopia, policy implementation practice challenged by public leadership problems like policy leadership structure and commitment, leadership capacity and coordination, work cooperate with communities, private sectors, and competencies of leaders or managers in general lack of corporate leadership faced [18]. Similarly, there are deficiencies in terms of effectiveness, the efficiency of the program's implementation [19]. The why and what of these practice gaps are related to leadership aspects. Moreover, as [7] administrators' incompetency to administer and provide services to their residents have affected the level of popular participation in Addis Ababa City Government particularly in Yeka Sub City Weredas. The question that comes to the researcher's mind was that where is the failure in terms of leading policy implementation process in an effective manner and does 
leadership has a direct influence in the process of policy implementation?

The government has embarked on a series of reform programs that need continual research. In case, there were studies related to leadership effectiveness by [20] the leader's capacity by $[7,21]$. The studies mainly focused on identifying challenges of leadership and policy implementation but not on identifying the relationship between specific leadership styles and effective policy implementation processes. Leadership is a common problem in most public service organizations' in Ethiopia and are accountable for policy implementation failure [20]. Unlike the studies presented above, this study tried to investigate the relationship between specific leadership styles and the effectiveness of the policy implementation process. Therefore, it is justifiable to conduct this study to contribute and cover the gap in relation to leadership style and policy implementation.

Policy implementation gap also emanates from leadership development practice because; leadership development and an appointment done through political appointments, rather than career posts depend on the leader's competencies [22]. Some of the policy statements/elements could not implemented effectively because of civil servant intrinsic deficiencies and general impracticality, as perceived by the actual policy implementer and the civil servant [6]. Hence, which leadership style is more appropriate to the effective implementation of policies? This study expected to contribute to the efforts made by different bodies to address the problems hindering the effective implementation policies in the context of Addis Ababa City Government by generate new insights regarding the relationship between leadership styles and policy implementation.

Generally, latest adjustments through which the public sector in Ethiopia including Addis Ababa City Government have been going. It is essential to analyze the affiliation of distinctive management patterns and the effectiveness of the policy implementation process. Therefore, the primary contribution of this study used to be to look into the impact of specific leadership styles of leaders i.e., transactional, transformational and laissezfaire on the effectiveness of policy implementation procedure and reply the query of how first-class to effectively put in force policies based on the views of leaders and followers in the same context.

\subsection{Research Questions}

The study aimed to explore the influence of leaders' leadership styles on the effectiveness of the policy implementation process. It was guided by the following specific research questions:

What type of leadership style more practiced by leaders of selected ${ }^{1}$ government public sectors in Addis Ababa City Government?

To what extent do the effectiveness of implementation

1 Education, Trade and Industry, Labor and social affairs, Public service and human resources development and Micro and Small-scale Enterprise. process of policies in selected government public sectors in Addis Ababa City Government?

What are the effects of transformational, transactional, and laissez-faire leadership styles on the effective implementation of policies in selected government public sectors in Addis Ababa City Government?

What type of relationships does exist between transformational, transactional, and laissez-faire leadership styles and the effectiveness of policy implementation in selected government public sectors in Addis Ababa City Government?

Which leadership style more promotes effective implementation of policies in selected government public sectors in Addis Ababa City Government?

\subsection{Scope of the Study}

The study delimited to public sectors in Addis Ababa City Government. Policy implementation process effectiveness measured by policy-practice alignment, stakeholder engagement, active implementation or communication, ongoing assessment and support, and transparency. Leadership styles covered in this study were transactional, transformational, and laissez-faire.

\section{Research Methodology}

\subsection{Research Design}

The main purpose of this study is to explore the influence of leaders' leadership styles on the effectiveness of the implementation process of policies in selected government public sectors in Addis Ababa City Government. Therefore, the study used a descriptive survey design that uses a crosssectional survey methodology. This design were found to be relevant for the study. This design seeks to establish relations between variables serving as a basis for explaining the phenomena described [23].

A descriptive survey design enables one to trace relationships among two or more variables to gain greater situational insight [24]. In this study, the researcher identifies the leadership styles of the managers to explain the relationships between leadership styles and the effectiveness of the policy implementation process. Based on the research approach, the study followed a quantitative approach that focused on investigating effects and correlation of variables. It is justifiable that the testing relationship of different variables needs quantitative data.

\subsection{Data Type and Sources}

The primary data collected for this study were from primary sources. The primary sources were leaders or managers and employees because these sample groups were relevant to this study to identify the leadership styles exercised and the practice of policy implementation process at the selected government public sectors in Addis Ababa City Government. 


\subsection{Population, Sampling Technique and Sample Size}

\subsubsection{Population}

The population of this study covered public leaders and servants of Addis Ababa city government that comprises of ten sub-cities. The city government selected because the researcher observed the inefficiency and ineffectiveness of policy implementation practice in the work experience.

\subsubsection{Sampling Technique and Sample Size}

Studying the whole population is impossible. For this reason, the researcher picked a representative sample of the whole population. Thus, for the data collection, a three-stage sample design (multi-stage) sampling technique was applied.

Stage 1: selecting sub-cities: Sub cities organized in some way i.e., with the same governance structure and policies are designed from the center (from the council of people) at city government level moreover, leaders and managers appointed in a similar way. Therefore, based on these homogeneity for this research purpose $3(30 \%)$ sub-cities were selected by simple random (lottery method). Even though the sample size is different according to the different nature of studies, as a rule of thumb, most commonly $20-30 \%$ sample is sufficient for quantitative study [25].

Stage 2: selecting public sectors, all public sectors categorized under some governance and leadership. Moreover, policies forced to implement in similar ways on similar areas and leaders and employees appointed in similar systems to all sectors. Therefore, these homogeneity or assumption leads the researcher to choose five public sectors among all government public sectors by simple random (lottery method). The study was focused on sub-city level sectors because of the mostly policy implementation process as a stage exercised at the sub-city level. However, Wereda simply considered as another name of the previous Kebele because there are old memories still and this perception significantly affects the level of popular participation in Weredas, and Wereda council roles seem to have been mixed with that of the executive branch [7].

Stage 3: selecting managers or leaders and employees: From selected three sub-cities and five public sectors at subcity-level, leaders or managers and employees were included as a sample by simple random method. This method is important to give equal chance to all members of the population to be chosen as a sample and give confidence to generalization [23]. By using the simplified formula, the sample size calculated from the total population of 579 as follows.

$$
\mathrm{n}=\frac{\mathrm{N}}{1+\mathrm{N}(\mathrm{e})^{2}}\left(\mathrm{n}=\frac{579}{1+579(0.05)^{2}}=237\right)
$$

Where $\mathrm{n}$ is the sample size, $\mathrm{N}$ : is the population size, $\mathrm{e}=$ acceptable error $(0.05)$.

Table 1. Distribution of Sample across sub-cities and sectors (summary).

\begin{tabular}{|c|c|c|c|c|c|c|c|c|c|c|c|}
\hline \multicolumn{2}{|c|}{ Sub-city } & & Yeka & NSL & Bole & Total & & Yeka & NSL & Bole & Total \\
\hline & & \multicolumn{5}{|c|}{ Population } & \multicolumn{5}{|c|}{ Sample } \\
\hline \multirow{18}{*}{ Sector } & \multirow{3}{*}{ Education } & $\mathrm{M}$ & 22 & 19 & 16 & 57 & $\mathrm{M}$ & 10 & 8 & 8 & 26 \\
\hline & & $\mathrm{F}$ & 10 & 16 & 10 & 36 & $\mathrm{~F}$ & 4 & 7 & 3 & 14 \\
\hline & & $\mathrm{T}$ & 32 & 35 & 26 & 93 & $\mathrm{~T}$ & 14 & 15 & 11 & 37 \\
\hline & \multirow{3}{*}{ Trade and Industry } & M & 25 & 25 & 27 & 77 & M & 11 & 9 & 10 & 30 \\
\hline & & $\mathrm{F}$ & 23 & 20 & 13 & 56 & $\mathrm{~F}$ & 9 & 10 & 6 & 25 \\
\hline & & $\mathrm{T}$ & 48 & 45 & 37 & 137 & $\mathrm{~T}$ & 20 & 19 & 16 & 55 \\
\hline & \multirow{3}{*}{$\begin{array}{l}\text { Labor and social } \\
\text { affairs }\end{array}$} & M & 20 & 15 & 11 & 46 & M & 10 & 5 & 7 & 22 \\
\hline & & $\mathrm{F}$ & 22 & 21 & 20 & 63 & $\mathrm{~F}$ & 7 & 8 & 8 & 23 \\
\hline & & $\mathrm{T}$ & 42 & 36 & 37 & 115 & $\mathrm{~T}$ & 17 & 13 & 15 & 45 \\
\hline & \multirow{3}{*}{$\begin{array}{l}\text { Public service and } \\
\text { human resources } \\
\text { development }\end{array}$} & M & 23 & 27 & 21 & 71 & M & 12 & 12 & 6 & 30 \\
\hline & & $\mathrm{F}$ & 12 & 13 & 9 & 34 & $\mathrm{~F}$ & 3 & 5 & 4 & 12 \\
\hline & & $\mathrm{T}$ & 35 & 37 & 30 & 105 & $\mathrm{~T}$ & 15 & 17 & 10 & 42 \\
\hline & \multirow{3}{*}{$\begin{array}{l}\text { Micro and Small-scale } \\
\text { Enterprise }\end{array}$} & M & 23 & 24 & 25 & 72 & M & 6 & 10 & 7 & 23 \\
\hline & & $\mathrm{F}$ & 21 & 23 & 23 & 67 & $\mathrm{~F}$ & 11 & 8 & 13 & 32 \\
\hline & & $\mathrm{T}$ & 44 & 47 & 48 & 137 & $\mathrm{~T}$ & 17 & 18 & 20 & 55 \\
\hline & \multirow{3}{*}{ Total } & & & & M & 323 & & \multirow{3}{*}{ Total } & & $\mathrm{M}$ & 131 \\
\hline & & & & & $\mathrm{F}$ & 256 & & & & $\mathrm{~F}$ & 106 \\
\hline & & & & & $\mathrm{T}$ & 579 & & & & $\mathrm{~T}$ & 237 \\
\hline
\end{tabular}

Key: $\mathrm{M}=$ male, $\mathrm{F}=$ female, $\mathrm{T}=$ total, $\mathrm{NSL}=$ Nifas Silk Lafto.

\subsection{Methods of Data Collection}

Data for this study were collected by using a structured self-complete research questionnaire that was distributed to the sample and was collected after a few days. The questionnaire designed to measure leadership styles were adopted from the Multifactor Leadership Questionnaire (MLQ) and public policy literature. Thus, respondents were got the same question and in the same format. Questionnaires enabled the collection of original data from the sample of the population within a short time and at low cost for purposes of describing the entire population [23].

The questionnaire was in three parts. Part one about the sample demographics. Part two the leadership styles and part three about public policy effectiveness. All of the questions were write in English and Amharic, as the researcher believes that respondents could understand the questions in these two languages. The questionnaire that was administered to measure policy implementation effectiveness structure with 
closed-ended type 5 point Likert scale (strongly agree to strongly disagree) and whereas, the questionnaire to identify the practice of the selected leadership styles scaled as never, sometimes, often, frequently and always. It helps the researcher to know respondents, feeling, and leads the respondents to have opportunities to choose.

\subsection{Data Analysis Technique}

The characteristic of respondents was analyzed by using frequency and percentage whereas the other data were analyzed by using descriptive statistics like percentages, mean, and standard deviation. Inferential statistics such as Pearson Product Moment correlation and multiple regressions were used to analyze the extent of the influence of leadership styles on policy implementation process effectiveness. The statistical tools were chosen based on the nature of the study and the research questions. The statistical analyses were conducted using SPSS version 23.

Table 2. the research methods followed in conducting the study (summary).

\begin{tabular}{|c|c|c|c|c|}
\hline Objectives of the Study & Respondents & $\begin{array}{l}\text { Sampling } \\
\text { methods }\end{array}$ & $\begin{array}{l}\text { Data collection } \\
\text { techniques }\end{array}$ & Data analysis techniques \\
\hline $\begin{array}{l}\text { Leadership style more practiced by leaders } \\
\text { Extent of PPI effectiveness } \\
\text { Transformational Transactional \& laissez-faire, } \\
\text { leadership styles and/on the effectiveness of } \\
\text { policy implementation process }\end{array}$ & $\begin{array}{l}\text { Managers, or leaders and } \\
\text { employees or experts of } \\
\text { Addis Ababa City } \\
\text { Gouvernement selected } \\
\text { public sectors }\end{array}$ & $\begin{array}{l}\text { Simple } \\
\text { random } \\
\text { sampling }\end{array}$ & $\begin{array}{l}\text { Closed ended } \\
\text { Questionnaire }\end{array}$ & $\begin{array}{l}\text { Descriptive statistics (percentages, } \\
\text { mean, standard deviation), } \\
\text { Inferential statistics } \\
\text { (Pearson Product Moment } \\
\text { correlation, multiple regression) }\end{array}$ \\
\hline
\end{tabular}

Source: own (Researcher).

\subsection{Validity and Reliability of the Instruments}

The study has adopted the scales, which had validated elsewhere because in measuring leadership styles the study adapted the Multifactor Leadership Questionnaire (MLQ) developed by $[26,27]$ and modified to fit the context of the study. To measure the effectiveness of public policy implementation the study was used the indicators of measuring policy effectiveness adopted from the literature. Furthermore, for validating the content of the questionnaire the researcher has conducted a pilot test on individuals who were not part of the sample of the study and work at Kirkos sub-city which was not the sample of the study. Thus, the participants recommend that modifying five items of the questionnaire and change the language more understandable Amharic language. Accordingly, before administering the questionnaire the researcher modified the 5 items and change the questionnaire into the Amharic language.

The reliability of the Multifactor Leadership Questionnaire (MLQ) for each leadership factor ranges from .74 to .91 . It is the most widely used instrument to assess leadership styles [28]. The questionnaire that was developed to measure the effectiveness of policy implementation was tested and the coefficient alpha (also known as Cronbach Alpha) analyzed. The coefficient of reliability test (Cronbach alpha) for the questionnaire items was carried out using SPSS version 23.

The value of alpha for the questionnaire that was administered to measure policy implementation effectiveness is .959. Moreover, the variables/indicators of policy implementation effectiveness were identified from the literature of public policy like [16] and [29]. That of questionnaire items measured the leadership styles of managers or leaders adapted from the Multifactor Leadership Questionnaire (MLQ) developed by [26], [27], and items were modified to fit the context of the study. The reliability test result of items that were measured policy implementation effectiveness indicated in table 4 below.
Table 3. Reliability Test Result of SPSS Output.

\begin{tabular}{ll}
\hline Reliability Statistics & \\
\hline Cronbach's Alpha & N of Items \\
\hline .959 & 31 \\
\hline
\end{tabular}

Source: Computation from Survey Data (2020).

Consequently, the reliability Multifactor Leadership Questionnaire (MLQ) employed in this study ranges from 0.74 to 0.91 . Besides, the alpha values items that were measure policy implementation of effectiveness were 0.959 , which is more than 0.7 and therefore the reliability of the questionnaire is good. Because the coefficient which reflects homogeneity among a set of items varies from 0 to 1 . Good reliability should produce at least a coefficient value of 0.70 [30]. The values of Cronbach's alpha more than 0.7 are good.

\section{Data Presentation, Analysis and Discussion}

\subsection{Response Rate and Description of Respondents' Characteristics}

To address the research objectives, questionnaires were administered to a complete of 270 leaders and experts. Among these, 237 are properly filled and returned (i.e., the response rate is $87 \%$ ). The response rate indicated quite $80 \%$ response of the planned. Therefore, it enables the researcher to investigate interpret and conclude the information to the population.

The research participants of the study background information their sex, age, qualification, work position, experience, the world they work, and therefore the sub-city. The results obtained from the structured questionnaire presented on figures below respectively.

\subsubsection{Sex}

Figure 3 below displays the sex distribution of the sample 
leaders and experts. The figure showed from the sample 237 majorities $(62 \%)$ of respondents were male and $(37 \%)$ were female. It implies that the researcher got an opportunity of collecting data from different views in sex-wise.

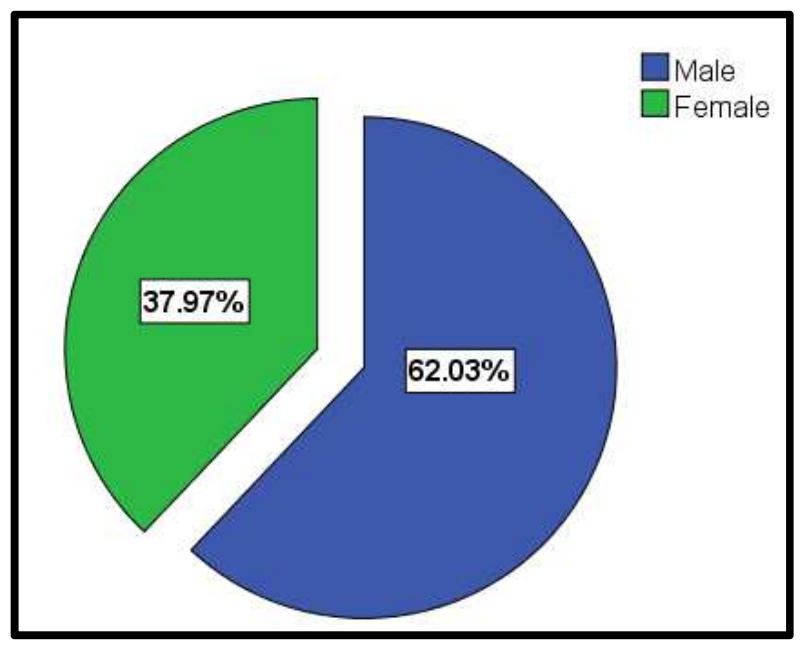

Source: Field survey, 2020

Figure 3. Sex of Respondent $(n=237)$.

\subsubsection{Age}

Figure 4 below displays the age distribution of the sample. Because, the figure shows regarding the age category most of the respondents, $(58 \%)$ were between $31-45$ years. The remainder $(36 \%)$ were between the ages of $18-30$ and $(6 \%)$ were above 45 years. This means the data were collected from the respondents who were well matured and may provide grasp information and data for the study.

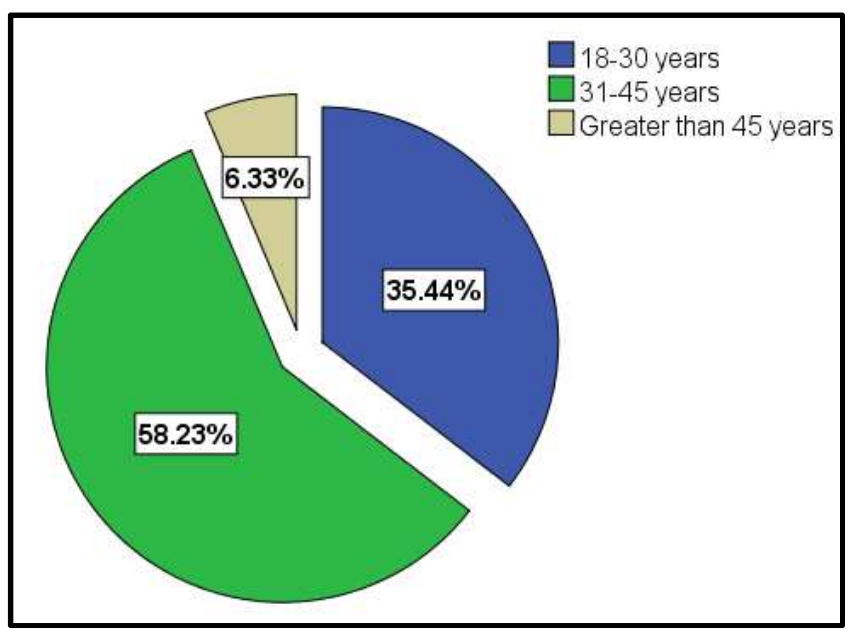

Source: Field survey, 2020

Figure 4. Age of Respondent $(n=237)$.

\subsubsection{Education Level}

Figure 5 below illustrates the education level of respondents. As it displays below the bulk of the respondents (79\%) were first-degree holders. The other (11\%) were diploma holders and (8\%) were second-degree holders. Moreover, the smallest amount (3\%) were certificate holders. The figure exhibits that over $(85 \%)$ of the respondents were first and second-degree holders. Hence, it is concluded that over $1 / 2$ the samples have a primary degree. This composition of the education level of the sample gives chance to gather a spread of views and understanding about the study.

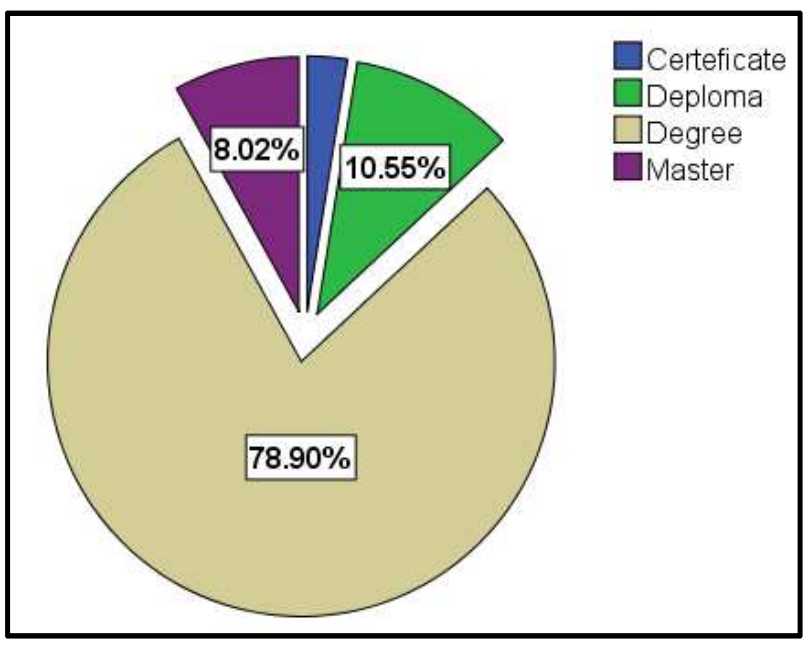

Source: Field survey, 2020

Figure 5. Education Level of Respondent $(n=237)$.

\subsubsection{Work Position}

Figure 6 below indicate that $(76 \%)$ of the respondent were experts while (24\%) were leaders or managers. The composition is vital to urge accurate data of the performance of policy implementation and evaluation of leaders' leadership style.

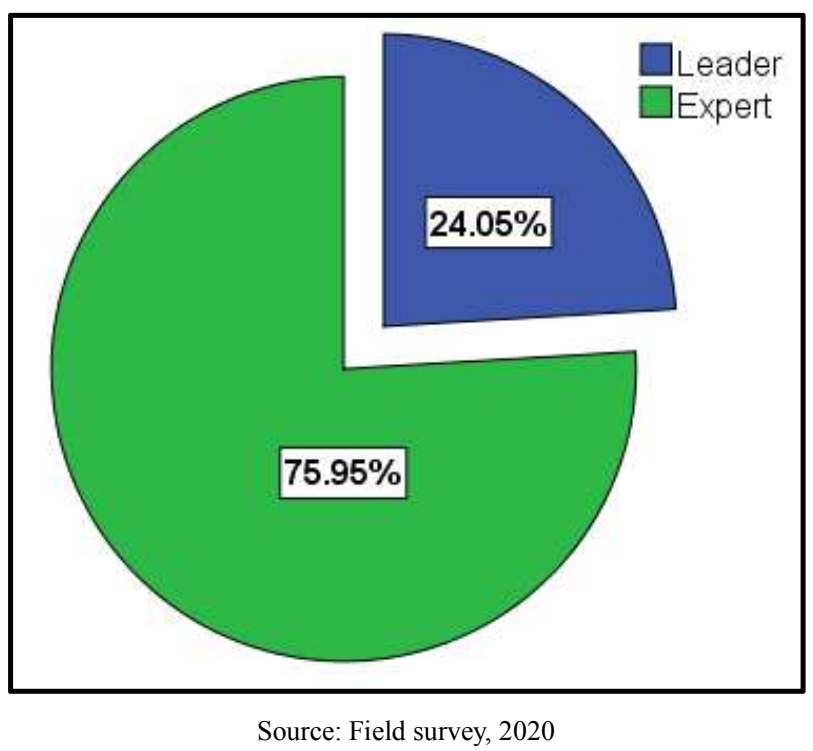

Figure 6. Work Position of Respondent ( $n=237)$.

\subsubsection{Work Experience}

Regarding work experience, figure 7 below displays that the majority $(76 \%)$ of the sample have the overall experience of greater than five years while $(24 \%)$ of the sample have $2-5$ years. The information shows that majority of the respondents have adequate knowledge about the 
implementation of public policies and leadership practice.

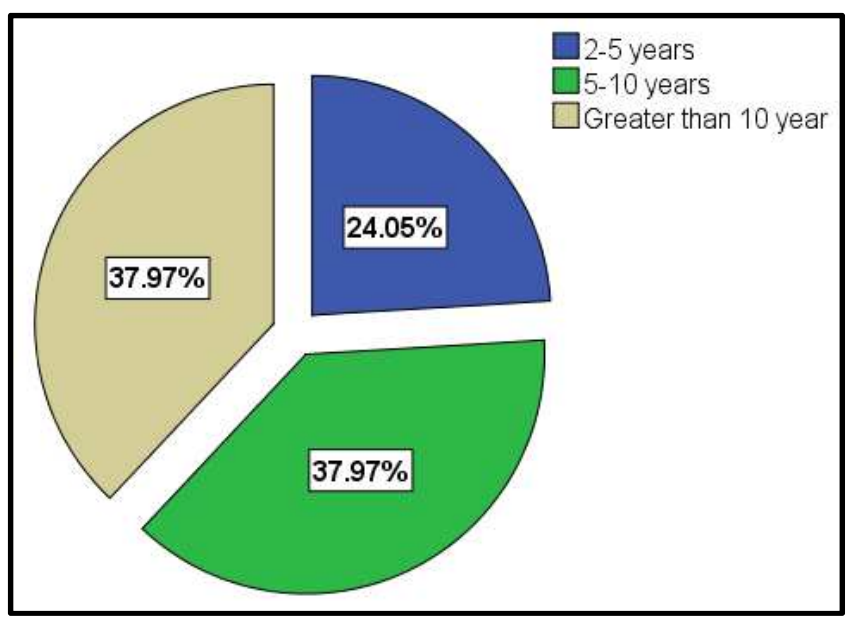

Source: Field survey, 2020

Figure 7. Work Experience of Respondent.

\subsubsection{Sector}

Figure 8 below indicates the sector that the sample respondents work. As it shows, majority of the respondent were $(23 \%)$ were works at the micro and small enterprise, $(22 \%)$ at trade and industry, (19\%) labor and social, (18\%) public service and human resource development and (18\%) were from the education sector. The frequencies are almost in proportion. It implies the data could show the variation in implementing policies and leadership styles used.

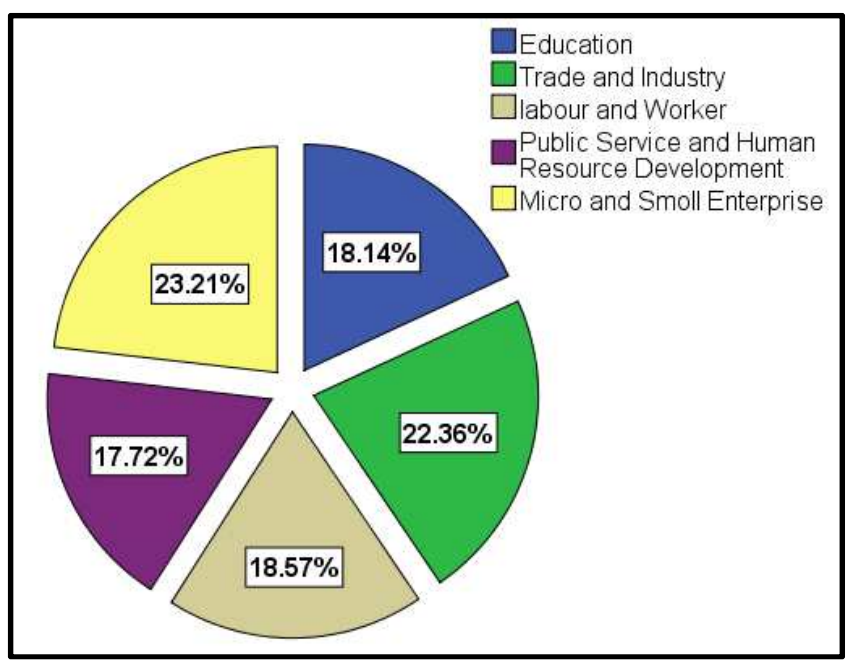

Source: Field survey, 2020

Figure 8. Respondent in Sector ( $n=237)$.

\subsubsection{Sub City}

As figure 9 below illustrates, respondents were asked to indicate the sub-city they work. In the case, the majority of the respondents $(42 \%)$ have worked at Nifas Silk Lafto, $(36 \%)$ at Yeka-Sub City and the rest (22\%) at Bole Sub-City. It is according to the population of staff as indicated in chapter three. The composition indicates respondents were from the different work-related environment. It enables the researcher to have the data that varied in the experience of implementing policies and the used leadership styles.

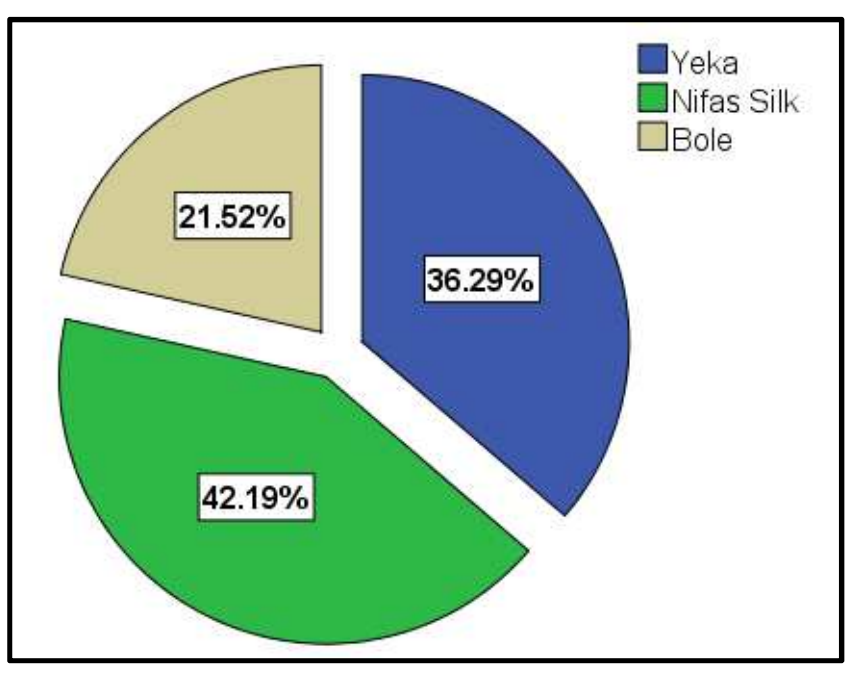

Source: Field survey, 2020

Figure 9. Sub city of Respondent ( $n=237)$.

\subsection{Data Presentation and Analysis with Related to Research Questions (RQs)}

\subsubsection{RQ 1: Leadership Style/s Frequently Used by Leaders}

i. Transformational Leadership Style

Table 3 below describes the frequency of practicing transformational leadership style in line with the four-set of transformational leadership style indicators: Inspirational Motivation, Idealized Influence, Intellectual Stimulation, and Individual Consideration generally and with eleven specific items. the info within the table exhibits the bulk of respondents (54\%) indicated that there are leaders who used the transformational leadership style often, (37\%) were respond leaders practiced transformational leadership style in selected government public sectors in Addis Ababa City Government the opposite $(3 \%)$ and $(5 \%)$ respondent agreed that leaders use transformational leadership style always and never respectively. It implies quite (90\%) respondents revealed, leaders within the selected government public sectors in Addis Ababa City Government practiced the transformational leadership style in leading followers. The mean 4 also indicates the frequent practice of the transformational leadership style. The $\mathrm{SD}=0.6$ which does not show a major deviation from the expected mean $=3$ (often).

In detail, table 4 below indicates the practice of the main indicators of the transformational leadership style (Inspirational Motivation, Idealized influencing, Intellectual Stimulation and Individual Consideration).

The table 3 below illustrates majorities (52\%) (Mean=4 and $\mathrm{SD}=0.7)$ of respondents indicate leaders often lead by Inspirational Motivation and it indicate leaders often leading trough inspirational motivation. The opposite (36\%), (7\%) and $(5 \%)$ of the respondents indicated that leaders frequently, always and sometimes respectively exercise Inspirational Motivation in their leadership. In terms of Idealized influencing followers, the bulk (41\%) (Mean=3 and $\mathrm{SD}=0.9)$ 
indicated often. While, $(37 \%),(11 \%),(7 \%)$ and $(3 \%)$ of the respondents agreed that leaders frequently, sometimes, never and always practice Idealized influencing followers in leading the sectors. the opposite indicator of the transformational leadership style was Intellectual Stimulation to guide followers. just in case the bulk of the respondents $(41 \%)($ Mean $=3$ and $\mathrm{SD}=0.9)$ agreed that leaders characterize by Intellectual Stimulation in leading followers. The opposite $(30 \%),(21 \%)$ and $(8 \%)$ reacted that leaders practice
Intellectual Stimulation frequently, sometimes and always correspondingly. While (47\%) (Mean=3 and $\mathrm{SD}=0.9)$ of the respondents evidenced that leaders used Individual Consideration to guide the followers frequently. On the opposite hand, (29\%), (16\%), (5\%) and $(3 \%)$ of the respondents agreed leaders practice Individual Consideration behavior of transformational leadership style often, sometimes, always and never respectively.

Table 4. Practice of Transformational Leadership Styles ( $n=237)$.

\begin{tabular}{|c|c|c|c|c|c|c|c|c|c|}
\hline Leadership Style & & Never & Sometimes & Often & Frequently & Always & Total & Mean & SD \\
\hline \multirow{2}{*}{ Transformational } & Count & & 7 & 128 & 90 & 12 & 237 & \multirow{2}{*}{4} & \multirow{2}{*}{0.6} \\
\hline & $\%$ & & $3 \%$ & $54 \%$ & $37 \%$ & $5 \%$ & $100 \%$ & & \\
\hline \multirow{2}{*}{ Inspirational Motivation } & Count & & 11 & 123 & 86 & 17 & 237 & \multirow{2}{*}{4} & \multirow{2}{*}{0.7} \\
\hline & $\%$ & & $5 \%$ & $52 \%$ & $36 \%$ & $7 \%$ & $100 \%$ & & \\
\hline \multirow{2}{*}{ Idealized Influence } & Count & 16 & 27 & 97 & 91 & 6 & 237 & \multirow{2}{*}{3} & \multirow{2}{*}{0.9} \\
\hline & $\%$ & $7 \%$ & $11 \%$ & $41 \%$ & $37 \%$ & $3 \%$ & $100 \%$ & & \\
\hline Intellectual Stimulation & $\%$ & & $21 \%$ & $41 \%$ & $30 \%$ & $8 \%$ & $100 \%$ & 3 & 0.9 \\
\hline \multirow{2}{*}{ Individual Consideration } & Count & 7 & 37 & 69 & 111 & 12 & 237 & \multirow{2}{*}{3} & \multirow{2}{*}{0.9} \\
\hline & $\%$ & $3 \%$ & $16 \%$ & $29 \%$ & $47 \%$ & $5 \%$ & $100 \%$ & & \\
\hline
\end{tabular}

Source: Field survey, 2020.

ii. Transactional and Laissez-faire Leadership Styles

1) Transactional Leadership Style

In this study, Table 5 below identified the practice of transactional leadership style. Findings showed that the bulk of the respondent $(45 \%)$ and $(33 \%)$ (Mean=4 and $\mathrm{SD}=0.8)$ agreed that leaders in selected public sectors in Addis Ababa city administration frequently and sometimes used transactional leadership style. The opposite (14\%) and (8\%) of the respondents argued that leaders of the study area sometimes and always showed transactional leadership style within the workplace. Therefore, because the majority of the respondents' responses indicated there are leaders within the selected public sectors of Addis Ababa city government who practiced transactional leadership style.

To measure the practice of transactional leadership style the study has categorized the feature of transactional leadership style into Contingent Reward and Management by Exception. The finding in table 6 below showed the bulk of the respondent $(33 \%)$ and $(30 \%)$ (Mean=3 and $\mathrm{SD}=1)$ respond that leaders leading through Contingent Reward frequently and infrequently respectively. While, (13\%), $(12 \%)$ and $(12 \%)$ of the respondents agreed that leaders lead through Contingent Reward never, sometimes and always respectively. Similarly, the majority of the frequency (49\%) and $(25 \%)(\mathrm{Mean}=4$ and $\mathrm{SD}=0.8)$ indicates the response of frequently and infrequently respectively for the practice of the feature Management by Exception. The opposite (17\%) and $(10 \%)$ correspondingly responded that leaders always and sometimes practice leadership by Management by Exception (active).

Table 5. Practice of Transactional and Laissez-faire Leadership Styles $(n=237)$.

\begin{tabular}{|c|c|c|c|c|c|c|c|c|c|}
\hline Leadership Style & & Never & Sometimes & Often & Frequently & Always & Total & Mean & SD \\
\hline \multirow{2}{*}{ Transactional } & Count & - & 33 & 78 & 107 & 19 & 237 & \multirow{2}{*}{4} & \multirow{2}{*}{0.8} \\
\hline & $\%$ & - & $14 \%$ & $33 \%$ & $45 \%$ & $8 \%$ & $100 \%$ & & \\
\hline \multirow{2}{*}{ Contingent Reward } & Count & 30 & 29 & 71 & 78 & 29 & 237 & \multirow{2}{*}{3} & \multirow{2}{*}{1} \\
\hline & $\%$ & $13 \%$ & $12 \%$ & $30 \%$ & $33 \%$ & $12 \%$ & $100 \%$ & & \\
\hline \multirow{2}{*}{ Management by Exception (Active) } & Count & - & 23 & 58 & 117 & 37 & 237 & \multirow{2}{*}{4} & \multirow{2}{*}{0.8} \\
\hline & $\%$ & - & $10 \%$ & $25 \%$ & $49 \%$ & $17 \%$ & $100 \%$ & & \\
\hline
\end{tabular}

Source: Field survey, 2020.

\section{2) Laissez-faire Leadership Styles:}

Table 6 below also indicates the frequency of practicing Laissez-faire leadership style. The table illustrate the majority of the respondent (45\%) and (30\%) (Mean=3 and $\mathrm{SD}=0.9$ ) showed the agreement that leaders used Laissezfaire leadership style frequently and often respectively. In addition, the other $(14 \%),(6 \%)$ and $(6 \%)$ of the respondents responded that sometimes, always and never respectively. It was observed that there is the practice of Laissez-faire Leadership Styles in decisions and authority passing by leaders of selected government public sectors in Addis Ababa City Government. 
Table 6. Practice of Laissez-faire Leadership Styles $(n=237)$.

\begin{tabular}{|c|c|c|c|c|c|c|c|c|c|}
\hline Leadership Style & & Never & Sometimes & Often & Frequently & Always & Total & Mean & SD \\
\hline Laissez-faire & $\begin{array}{l}\text { Count } \\
\%\end{array}$ & $\begin{array}{l}13 \\
6 \%\end{array}$ & $\begin{array}{l}33 \\
14 \%\end{array}$ & $\begin{array}{l}107 \\
45 \%\end{array}$ & $\begin{array}{l}70 \\
30 \%\end{array}$ & $\begin{array}{l}14 \\
6 \%\end{array}$ & $\begin{array}{l}237 \\
100 \%\end{array}$ & 3 & 0.9 \\
\hline
\end{tabular}

Source: Field survey, 2020 Key: SD= Standard Deviation.

iii.Leadership Style/s More Practiced by Leaders (Summary)

Figure 10 below the display, the comparison leadership styles practiced by leaders of selected government public sectors in Addis Ababa City Government. Therefore, the figure showed leaders practiced transactional leadership style most often and transformational and Laissez-faire often. Consequently, the research finding ends up in induce those leaders within the selected government public sectors in national capital City Government to exercise transactional leadership style frequently followed by transformational and Laissez-faire leadership styles. Moreover, the research result ends up in the interpretation of there's a variation in using leadership styles one and another.

\subsubsection{RQ 2: Effectiveness of Public Policies Implementation Process}

To measure the effectiveness of the implementation policies the study adopted [16] five quality indicators of effective policy development and implementation. These indicators/features were Policy-Practice Alignments, Stakeholders Engagement in Policy Implementation, Active Implementation, or Communication of Policies, Ongoing Evaluation of Policy Implementation, and Transparency of Policy Documents. Therefore, the researcher has incorporated these features as a Likert scale with 31 Likert items.

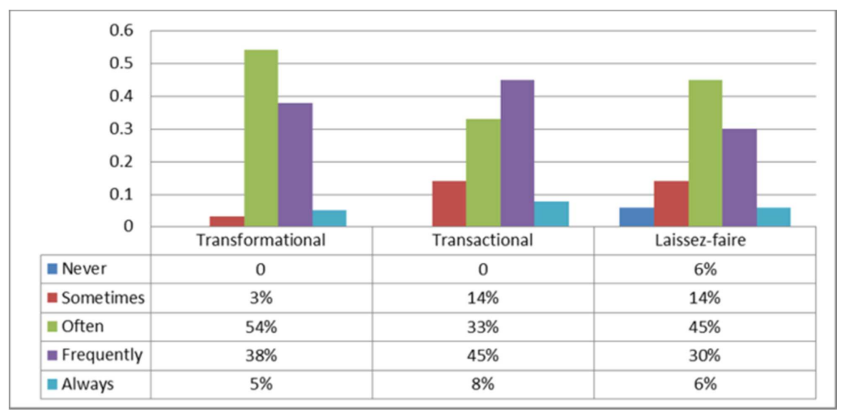

Source: Field survey, 2020

Figure 10. More Practiced Leadership Styles by Leaders ( $n=237)$.

The Figure 10 imply that just about half the respondents react positively i.e., $(42 \%)$ somewhat agreed and $(35 \%)$ agreed (Mean $=3$ and $\mathrm{SD}=0.9$ ) that the practice of aligning policy with practice is nice. The opposite $(23 \%)$ reacted to the statement negatively. The literature also suggests effective practices of the policy implementation process are more feasible when policy supports their implementation. While in terms of engaging stakeholders in policy implementation the majority of the respondents $(50 \%)$ agreed and $(33 \%)$ somewhat agreed (Mean $=3$ and $\mathrm{SD}=0.8$ ). While
$(13 \%)$ of the respondents responded negatively. Thus, this finding indicates the chosen public sectors within the study area participated in stakeholders.

In addition, Figure 10 also indicates active implementation or communication of policies. Here, the maority of the respondents respond in a very positive way i.e., (45\%) somewhat agreed and $(35 \%)$ agreed (Mean $=4$ and $\mathrm{SD}=$ $0.9)$. Means, the communication, or the implementation process of policies are somewhat active in selected public sectors in capital of Ethiopia city administration. The opposite (20\%) disagreed on the statement.

The other thing within the effective implementation of policies is an ongoing evaluation of policy implementation. The results displayed that, majority of the respondent (37\%) somewhat agreed and $(32 \%)$ agreed (Mean $=3$ and $\mathrm{SD}=0.9$ ) that revels there are somewhat ongoing evaluations of the implemented policies conducted in sectors. the opposite (28\%) disagreed with ongoing evaluations conducted in sectors. Hence, because the majority of the respondents revealed the chosen public sectors of town government evaluate the policy implementation practice in an ongoing manner.

Lastly, the respondent asked to reply to their agreement in making the policy and supporting documents transparent to the staff of the sectors additionally as stakeholders. In case, figure 11 below the evident majority of the respondents $(34 \%)$ and $(29 \%)($ Mean $=1$ and $\mathrm{SD}=1)$ respond agreed and somewhat agreed that documents are accessible in sectors. Hence, the finding also indicates the majority of the respondents positively react to the transparency of policy and supporting documents to the concerned bodies of the sectors.

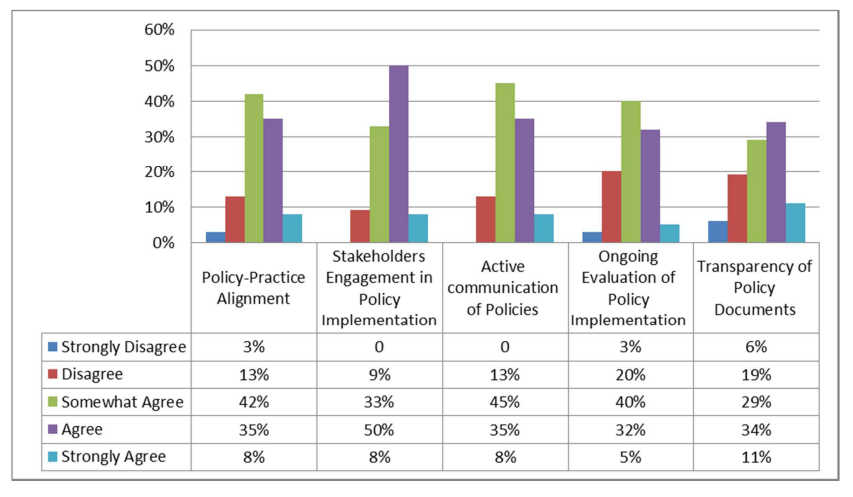

Source: Field survey, 2020

Figure 11. Effectiveness of Policy Implementation Practice $(n=237)$.

In summary, the policy implementation process somewhat effective with gaps because for most of the indicators of the effectiveness of policy implementation the majority frequency directs somewhat agreed. However, engaging 
stakeholders in policy implementation and making the policy and supporting documents transparent to the staff and stakeholders are in a good manner because the majority of respondents' agreement shows agreed. These gaps may because of leaders' leadership style because as objective three and four below indicates there are leadership styles practiced by leaders but not have a significant influence on public policy implementation process effectiveness.

\subsubsection{Descriptive Statistics on Leadership Style and Effectiveness of Policy Implementation Process}

The results of respondents' perceptions of the leadership style displayed by their immediate leaders revealed and therefore the agreement of respondents on the effectiveness of policy implementation process presented as follows.

Table 7 below shows that, the results of the analysis of the mean score and deviation within the response to Leadership Style and Effectiveness of Public Policies Implementation Process. The table indicates the mean of the imputed scores for the explanatory variables (transformational, Transactional, and Laissez-Faire styles) and the dependent variable i.e., Policy Implementation Process Effectiveness.

As the table indicates respondents perceived their leaders displaying a transformational leadership style sometimes to always and mean $=3.45, \mathrm{SD}=0.637$. The $\mathrm{SD}$ shows a variation in their responses. The range of the respondents indicated a minimum score of two that infers that some participants indicated that their leaders do not display this style while others (maximum $=5$ ) indicated that other subjects perceive their leaders/immediate supervision as always using this style.

Table 7 also indicates the perception of respondents supposed their immediate leaders display that Transactional leadership style and also the response ranged from 2 to 5 (sometimes to always) mean $=3.47, \mathrm{SD}=0.831$. It indicates leaders displayed transactional leadership style often. At the perception of respondents, there are leaders who practice transactional leadership style sometimes and always.

In similar, overall Laissez-Faire $(\mathrm{M}=3.22)$ reveals that immediate leaders of the participants displayed this style often. The standard deviation $(\mathrm{SD}=0.837)$ shows a variation in responses. The trend of the response indicated $(1=$ never to $5=$ always). It implies that there are leaders who never practice this sort of leadership and there are anther leaders who practice this leadership style always.

In terms of the effectiveness of policy implementation, $(\mathrm{M}=3.37)$ shows somewhat agreed that the implementation process of policies in selected public sectors is effective. The $\mathrm{SD}=0.647$ shows a variation in response. Some participants were disagreed (Minimum $=2$ ) et al. were strongly agreed.

Generally, the responses of the respondents ranged from never to always ( 1 to 5) for independent variables i.e., transformational, Transactional, and Laissez-Faire styles, and disagreed to strongly agreed (2 to 5) for the dependent variable i.e., Policy Implementation Process Effectiveness). The average also indicates 3 (often) for independent variables and three (somewhat agreed) for the dependent variable.
It implies that within the average response of the research participants there is the practice of leadership styles (independent variables) and Policy Implementation Process Effectiveness (dependent variable) across different sectors of sub-cities on the average starting from often to frequently. Moreover, the info revealed that there is a variation of using leadership styles and therefore the effectiveness of policy implementation level within the study area and these variations enable the researcher confident to regression and correlation analysis.

Table 7 below shows that, the results of the analysis of the mean score and deviation in the response on Leadership Style and Effectiveness of Public Policies Implementation Process. The table indicates the mean value of the imputed scores for the explanatory variables (transformational, Transactional and Laissez-Faire styles) and the dependent variable i.e., Policy Implementation Process Effectiveness.

As the table indicates respondents perceived their leaders displaying transformational leadership style sometimes to always and mean $=3.45, \mathrm{SD}=0.637$. The $\mathrm{SD}$ shows a variation in their responses. The range of the response indicated minimum score of 2 that infers that some participants indicated that their leaders do not display this style while others (maximum $=5$ ) indicated that other subjects perceives their leaders/immediate supervision as always using this style.

Table 7 also indicates the perception of respondents supposed their immediate leaders display that Transactional leadership style and the response ranged from 2 to 5 (sometimes to always) mean $=3.47, \mathrm{SD}=0.831$. It indicates leaders displayed transactional leadership style often. At the perception of respondents, there are leaders who practice transactional leadership style sometimes and always.

In similar, overall Laissez-Faire $(\mathrm{M}=3.22)$ reveals that immediate leaders of the participants displayed this style often. The standard deviation $(\mathrm{SD}=0.837)$ shows a variation in responses. The rage of the response indicated $(1=$ never to $5=$ always). It means that, there are leaders who never practice this style of leadership and there are anther leaders who practice this leadership style always.

In terms of effectiveness of policy implementation, $(\mathrm{M}=3.37)$ shows somewhat agreed that the implementation process of policies in selected public sectors is effective. The $\mathrm{SD}=0.647$ shows a variation in response. Some participants were dis agreed (Minimum $=2$ ) and others were strongly agreed.

Generally, the responses of the respondents ranged from never to always (1 to 5) for independent variables i.e., transformational, Transactional and Laissez-Faire styles and disagreed to strongly agreed (2 to 5) for the dependent variable i.e., Policy Implementation Process Effectiveness). The mean value also indicates 3 (often) for independent variables and 3 (somewhat agreed) for dependent variable.

It implies that in the average response of the research participants there is the practice of leadership styles (independent variables) and Policy Implementation Process Effectiveness (dependent variable) across different sectors of 
sub-cities on average ranging from often to frequently. Moreover, the data revealed that there is a variation of using leadership styles and the effectiveness of policy implementation level in the study area and these variations enable the researcher confident to regression and correlation analysis.

Table 7. Descriptive Statistics on Leadership Style and Effectiveness of Public Policies Implementation Process.

\begin{tabular}{|c|c|c|c|c|c|}
\hline & $\mathbf{N}$ & Minimum & Maximum & Mean & SD \\
\hline \multicolumn{6}{|l|}{ Independent Variables } \\
\hline Transformational & 237 & 2 & 5 & 3.45 & .637 \\
\hline Transactional & 237 & 2 & 5 & 3.47 & .831 \\
\hline Laissez-Faire & 237 & 1 & 5 & 3.22 & .837 \\
\hline \multicolumn{6}{|l|}{ Dependent Variable } \\
\hline Policy Implementation Process Effectiveness & 237 & 2 & 5 & 3.37 & .647 \\
\hline Valid N (listwise) & 237 & & & & \\
\hline
\end{tabular}

SD: Std. Deviation

Source: Field survey, 2020.

\subsubsection{Multiple Regression and Correlation Results}

RQ 3: the Influence of leadership Styles on the Effectiveness of Implementation of Public Policies

As the review of the literature (chapter 2) indicates either leadership styles expected to influence positively or negatively the effectiveness of the policy implementation process. The analysis and interpretation under this objective assure the expected influence. An effective leader influences followers in a desired manner to achieve desired goals and different leadership styles may affect organizational and policy implementation effectiveness [16].

i. Model Summary of the Regression Analysis

The following table 8 presents the results of multiple regressions, which revealed that the effectiveness of leadership styles (transformational, transactional, and Laissez-Faire) on the effectiveness of the implementation process of policies. The R Square of 0.107 showed that the variation of leadership style can account for $(11 \%)$ of the variance in the effectiveness of the implementation process of policies can be predicted by the leadership styles used (transformational, transactional, and Laissez-Faire). The remaining (89\%) of the variation in the effectiveness of the implementation process of policies cannot be explained by the variation of leadership style or could be explained by other variables, which are not included in the model. The finding implies leadership styles account for $(11 \%)$ of the variation in the effectiveness of the implementation process of policies.

Table 8. Model Summary of the Regression Analysis.

\begin{tabular}{lllll}
\hline Model & R & R Square & Adjusted R Square & Std. Error of the Estimate \\
\hline 1 & $.327^{\mathrm{a}}$ & .107 & .095 & .706 \\
a. Predictors: (Constant), Laissez-Faire, Transactional, Transformational & & \\
\hline
\end{tabular}

Source: Field survey, 2020

ii. ANOVA- Results of Multiple Regression Analysis

The ANOVA- Results of Multiple Regression Analysis presented at Table 9 below shows fitness test of the model results. Here, to test the fitness of the model there should be hypothesis. The null and alternative hypotheses for the ANOVA were:

Ho: all coefficients of independent variables (Transformational, Transactional and Laissez-Faire) are jointly insignificant (i.e., $\mathrm{B} 1=\mathrm{B} 2=\mathrm{B} 3=0$ ); and $\mathrm{H} 1$ : At least one of the coefficients of independent variables (Transformational, Transactional and Laissez-Faire) is significantly different from zero.

The result indicates the F-calculated is 9.282, which is large and $\mathrm{Sig}=0.000$ which is less than 0.05 or even $<0.01$. Thus, the decision is reject Ho that implies that the model is adequate (fit) and is worth keeping.

Table 9. ANOVA (Model fit test) - Results of Multiple Regression Analysis.

\begin{tabular}{|c|c|c|c|c|c|c|}
\hline Model & & Sum of Squares & Df & Mean Square & $\mathbf{F}$ & Sig. \\
\hline \multirow{3}{*}{1} & Regression & 13.876 & 3 & 4.625 & 9.282 & $.000^{\mathrm{b}}$ \\
\hline & Residual & 116.109 & 233 & .498 & & \\
\hline & Total & 129.985 & 236 & & & \\
\hline
\end{tabular}

Source: Field survey, 2020.

Influence of Transformational leadership Styles on the Effectiveness of Implementation of Public Policies.

In accordance with transformational theory, transformational (Visionary, Collaborative, Multidimensional, Participative, and Creative charismatic) influence Policy Actors such as Political Executive and 
Bureaucracy that will make the effective management of policy implementation [30]. Table 10 below presents the results of the coefficients of the regression model i.e., the finding of the influence of the transformational leadership style on the effectiveness of the policy implementation process. In the table the coefficients results indicates that transformational leadership positively predict effectiveness of policy implementation process, unstandardized $(\mathrm{B}=.347$ and sig $=0.000$ at $p<0.05)$. The results imply that leaders who used the transformational leadership style will contribute or influence significantly $(34.7 \%)$ of the effectiveness of the policy implementation process.
Studies assured that transformational leaders portray a clear vision, build consensus among participants, promote innovation, and are effective in managing change. His/her study also asserts that attributes of transformational leadership would be effective in tackling policy challenges, and policy actors- political executive and bureaucracy. Hence, the decision is to reject (Ho) there is no significant influence of the transformational leadership style on the effectiveness of the implementation of policies. It is concluded that the influence of the transformational leadership style has statistically significant in selected government public sectors in Addis Ababa City Government.

Table 10. Transformational leadership Styles on Effectiveness of Implementation of Policies.

\begin{tabular}{|c|c|c|c|c|c|c|}
\hline \multirow{2}{*}{\multicolumn{2}{|c|}{ Model }} & \multicolumn{2}{|c|}{ Unstandardized Coefficients } & \multirow{2}{*}{$\begin{array}{l}\text { Standardized Coefficients } \\
\text { Beta }\end{array}$} & \multirow{2}{*}{$\mathbf{T}$} & \multirow{2}{*}{ Sig. } \\
\hline & & B & Std. Error & & & \\
\hline \multirow[t]{2}{*}{1} & (Constant) & 2.137 & .318 & & 6.722 & .000 \\
\hline & Transformational & .347 & .074 & .323 & 4.697 & .000 \\
\hline
\end{tabular}

Source: Field survey, 2020.

Influence of Transactional leadership Styles on the Effectiveness of Implementation of Public Policies.

Transactional leadership theory focus on maintaining the status quo and the primary goal of the followers is to obey the instructions and commands of the leader [31].

The research finding related to the influence of transactional leadership style on the Effectiveness of Implementation of Policies presented at table 11 below. As the table, indicate, unstandardized $(\mathrm{B}=.097$ and $\mathrm{sig}=0.105$ at $\mathrm{p}<0.05)$. The results infer that leaders who used the transactional leadership style will contribute or influence $(9.7 \%)$ of the effectiveness of the policy implementation process. That means, transactional leadership style positively but not significantly influence/predict the effectiveness of the policy implementation process. Therefore, the decision is to fail to reject (Ho) there is no significant influence of transactional leadership style on the effectiveness of the implementation of policies in selected government public sectors in Addis Ababa City Government. The conclusion transactional leadership style has not influenced/predicts the effectiveness of the implementation of policies significantly because sig shows 0.105 which is greater than 0.05 .

However, as the research result indicated at research objective one in selected government public sectors in Addis Ababa City Government there are leaders who practice transactional leadership style often and frequently. Thus, those of leaders who use the transactional leadership style could not influence the implementation process of policies significantly. Thus, leaders who used transactional leadership style of the selected public sectors will not significantly contribute the effectiveness of policy implementation process.

Table 11. Transactional leadership Styles on the Effectiveness of Implementation of Policies.

\begin{tabular}{|c|c|c|c|c|c|c|}
\hline \multirow{2}{*}{\multicolumn{2}{|c|}{ Model }} & \multicolumn{2}{|c|}{ Unstandardized Coefficients } & \multirow{2}{*}{$\begin{array}{l}\text { Standardized Coefficients } \\
\text { Beta }\end{array}$} & \multirow{2}{*}{$\mathbf{T}$} & \multirow{2}{*}{ Sig. } \\
\hline & & B & Std. Error & & & \\
\hline \multirow[t]{2}{*}{1} & (Constant) & 2.137 & .318 & & 6.722 & .000 \\
\hline & Transactional & .097 & .059 & .124 & 1.630 & .105 \\
\hline
\end{tabular}

Source: Field survey, 2020.

Influence of Laissez-Faire leadership Styles on the Effectiveness of Implementation of Public Policies.

The laissez-faire style of leadership characterized by the leader interfering little in the decisions of the group and give freedom for the employees to make the decisions. In this sense, the leader avoids clarifying his or her expectations and resolving conflicts, as well as shifts his/her authority to the followers, deliberately abdicating the power to make decisions, which are delegated to the followers.

Table 12 below shows unstandardized $(\mathrm{B}=-.003$ and sig .957 at $p<0.05)$. The results infer that leaders who used the transactional leadership style will contribute or influence
$(-3 \%)$ of the effectiveness of the policy implementation process. That means, laissez-faire leadership style insignificantly negatively predicts the effectiveness of the policy implementation process. Therefore, the decision is to fail to reject (Ho) there is no significant influence of laissezfaire leadership style on the effectiveness of the implementation of policies in selected government public sectors in Addis Ababa City Government. The conclusion laissez-faire leadership style has not influenced the effectiveness of the implementation of policies significantly because sig shows 0.957 which is greater than 0.05 . It is clear that those leaders who practiced this leadership style has no 
contribution in the existing context of the study area.

Table 12. Laissez-Faire leadership Styles on the Effectiveness of Implementation of Policies.

\begin{tabular}{|c|c|c|c|c|c|}
\hline \multirow{2}{*}{ Model } & \multicolumn{2}{|c|}{ Unstandardized Coefficients } & \multirow{2}{*}{$\begin{array}{l}\text { Standardized Coefficients } \\
\text { Beta }\end{array}$} & \multirow{2}{*}{$\mathbf{T}$} & \multirow{2}{*}{ Sig. } \\
\hline & B & Std. Error & & & \\
\hline (Constant) & 2.137 & .318 & & 6.722 & .000 \\
\hline Laissez-Faire & -.003 & .055 & -.003 & -.054 & .957 \\
\hline \multicolumn{6}{|c|}{ Dependent Variable: Effectiveness of Policy Implementation Process } \\
\hline
\end{tabular}

Source: Field survey, 2020.

Consequently, the result of multiple regression model revealed that out of the features or styles of leadership the results of the study shows there is a significant positive influence/predicts of transformational leadership style on the effectiveness of the implementation of policies. While there is no significant influence of transactional leadership style on the effectiveness of the implementation of policies. In addition, there is no significant positive influence of laissezfaire leadership style on the effectiveness of the implementation of policies rather this style insignificantly negatively influence/predicts the effectiveness of the policy implementation process. However, there are leaders who exhibited both transactional and laissez-faire leadership style often and frequently in their daily work in selected government public sectors in Addis Ababa City Government.

RQ 4: Leadership Styles and Effectiveness of Implementation Process of Public Policies (Correlation Analysis)

i. Transformational Leadership Style and Effectiveness of Implementation of Public Policies

The fourth objective of the study was to establish the relationship between leaders' leadership style and the Effectiveness of the Implementation of Policies. Table 13 below shows the relationship between the Transformational Leadership Style and the Effectiveness of the Implementation of Policies. This study employed correlation analysis, which investigates the strength of the relationships between the studied dependent (Effectiveness of Implementation of Policies) and independent (transformational leadership style) variables. Thus, The strongest correlation result between the transformational leadership style and the Effectiveness of Implementation of Policies $(r=0.327$ and sig $=0.000)$.

Transformational leadership style has a positive impact on organizational change, a positive relationship on organizational innovation performance, and the leadership style moderates the relationship between organizational innovation capabilities, performances and has highly positive correlations with perceptions about executives' encouragement factors of its innovation climate [16]. According to Table 12, there is a significant positive relationship between transformational leadership style and the Effectiveness of the Implementation of Policies. It is concluded that there is a significantly strong positive relationship between the transformational leadership style and the Effectiveness of the Implementation of Policies because the sig value is less than 0.005 .

Table 13. Transformational Leadership Style and Effectiveness of Implementation of Policies- Correlations.

\begin{tabular}{llllll}
\hline & & Transformational & Transactional & Laissez-Faire & Policy Implementation Process Effectiveness \\
\hline \multirow{2}{*}{ Transformational } & Pearson Correlation & 1 & $.436^{* *}$ & -.062 & $.327^{* *}$ \\
& Sig. (2-tailed) & & .000 & .345 & .000 \\
& $\mathrm{~N}$ & 237 & 237 & 237 & 237 \\
**. Correlation is significant at the 0.01 level (2-tailed). & & & \\
*. Correlation is significant at the 0.05 level (2-tailed). & & & \\
\hline
\end{tabular}

Source: Field survey, 2020

ii. Transactional Leadership Style and Effectiveness of Implementation of Public Policies

Transactional leadership style is a style that assumes that people are motivated primarily by reward and punishment and leaders hand overall authority and responsibility that is the opposite thinking of an empowered employee [31]. Table 14 below indicates the correlation that resulted as being moderate is in between transactional leadership style and the Effectiveness of Implementation of Policies ( $\mathrm{r}=0.148$ and sig 0.023). Therefore, the relationship suggests positive and moderate and the conclusion made by observing the "P" value and it is less than 0.05 , which shows there is a significant positive relationship between transactional leadership style and the Effectiveness of Implementation of Policies.

Table 14. Transactional Leadership Style and Effectiveness of Implementation of Policies.

\begin{tabular}{|c|c|c|c|c|c|}
\hline & & Transformational & Transactional & Laissez-Faire & Policy Implementation Process Effectiveness \\
\hline \multirow{3}{*}{ Transactional } & Pearson Correlation & $.436^{* *}$ & 1 & -.049 & $.148^{*}$ \\
\hline & Sig. (2-tailed) & .000 & & .451 & .023 \\
\hline & $\mathrm{N}$ & 237 & 237 & 237 & 237 \\
\hline
\end{tabular}

Source: Field survey, 2020 
iii.Laissez-Faire Leadership Style and Effectiveness of Implementation of Policies

Contingency theories to leadership support a great deal of empirical freedom to leadership, (laissez-faire style) that the maximum freedom allowed to subordinates and leaders given freehand in deciding their policies and methods and to make independent decisions. Table 15 below illustrates the relationship between Laissez-Faire Leadership Style and Effectiveness of Implementation of Policies. As the table reveled, Laissez-Faire Leadership Style has negative and insignificant correlation with Effectiveness of Implementation of Policies $(r=-0.024, p=0.717$ which is greater than 0.05$)$.

Table 15. Laissez-Faire Leadership Style and Effectiveness of Implementation of Policies.

\begin{tabular}{|c|c|c|c|c|c|}
\hline & & Transformational & Transactional & Laissez-Faire & Policy Implementation Process Effectiveness \\
\hline \multirow{3}{*}{ Laissez-Faire } & Pearson Correlation & -.062 & -.049 & 1 & -.024 \\
\hline & Sig. (2-tailed) & .345 & .451 & & .717 \\
\hline & $\mathrm{N}$ & 237 & 237 & 237 & 237 \\
\hline
\end{tabular}

Source: Field survey, 2020.

In summary, the results of correlation analysis indicated transformational and transactional leadership styles have positive correlations with Effectiveness of Implementation of Policies. Moreover, this assured that transformational leadership style has significantly positive correlation with Effectiveness of Implementation of Policies more than transactional leadership. Surprisingly, Laissez-Faire Leadership Style has negative and insignificant correlation with Effectiveness of Implementation of Policies.

\subsubsection{RQ 5: the Leadership Style More Promotes the Effectiveness of Policy Implementation Process}

Effective leadership is a complex of different but related behaviors some of the more important behaviors are; being trustworthy, integrity, self-reflection, self-confidence, selfdirected, action- and results-oriented, communication (an effective leader is constantly aware of the importance of good communication), transparency, positive mindset and possesses clarity of direction [31].

From the multiple regression and correlation analysis conducted above, it is observed that transformational leadership significance positively influences or predicts and has a strong positive relationship with the Effectiveness of Policy Implementation. Transactional leadership has also an influence on the Effectiveness of Policy Implementation but not significance. The something, there is a relationship between Transactional leadership with the Effectiveness of Policy Implementation. However, Laissez-Faire Leadership Style no significant influence/prediction on the Effectiveness of Implementation of Policies and has a negative and insignificant correlation with Effectiveness of Implementation of Policies. Thus, if leaders exhibited transformational leadership more, the Effectiveness of Implementation of Policies will enhance in selected government public sectors in Addis Ababa City Government.

\subsection{Discussion of the Result}

\subsubsection{RQ 1: Leadership Style/s Frequently Used by Leaders}

At the result absolutely observed that leaders were leading with transformational leadership style features like Inspirational Motivation, Idealized Influencing, and
Intellectual Stimulation often, and regularly leading through Individual Consideration. Because the majority of the respondents agreed that leaders exercise these features of the transformational leadership style. From transformational theory, transformational leadership style particularly the feature of individual consideration motivates employees to perform better beyond expectations. From observations, it had been observed that respondents also support those leaders motivating followers through considering individual differences frequently in selected public sectors in Addis Ababa city administration.

Moreover, the result noted leaders in selected government public sectors in Addis Ababa City Government used a transactional leadership style frequently and sometimes through Contingent Reward and Management by Exception. This finding supported by the idea that was noted in theory $\mathrm{X}$ that the attitude of employees towards their working environment, managers may as a practical consequence adopt a standard low-trust view of the requirement to direct and control the efforts of their staff towards the achievement of organizational objectives. Theory $\mathrm{Y}$ also indicates that employee performance needs to not tend to external control for one to perform better. The result also indicates there are leaders who practice Laissez-faire Leadership Styles in selected government public sectors in Addis Ababa City Government frequently.

Hence, to conclude the Leadership Style/s Frequently Used by Leaders of the selected public sectors in the study area comparative analysis has done. As the section, 4.2 at the subsection Leadership Style/s More Practiced by Leaders (Summary) indicated leaders in selected government public sectors in Addis Ababa City Government used a transactional leadership style frequently and often through Contingent Reward and Management by Exception. This finding supported by the theory that the attitude of employees towards their working environment, managers may as a practical consequence adopt a traditional low-trust view of the need to direct and control the efforts of their staff towards the achievement of organizational objectives. Theory $\mathrm{Y}$ also indicates that employee performance needs not to be given external control for one to perform better. 


\subsubsection{RQ 2: Effectiveness of Public Policies Implementation Process}

The practice of the indicators/features of Policy-Practice Alignments, Stakeholders Engagement in Policy Implementation, Active Implementation, or Communication of Policies and Ongoing Evaluation of Policy Implementation in selected public sectors of city government of Addis Ababa has gaps because the majority response indicates somewhat agreed. This indicates the effectiveness of the implementation of policies did not satisfied leaders and bureaucrats enough.

The finding contradict with the theory of when policy and evidence-based practices not well aligned the policy can act as a barrier to achieving expected outcomes [18, 16]. Cooperative collaborative behavior between stakeholders to a policy, characterized by goal alignment, the event of strong personal relationships and a high willingness to share skills and knowledge is one among the success factors of policy implementation. Moreover, [16, 32] further stated that involve active communication among state, district, and leaders, soliciting input from stakeholders and gathering relevant data expected ineffectively implemented policies.

In general, the majority of the respondents revealed the chosen public sectors of the city government evaluate the policy implementation practice in an ongoing manner. The agreement level of respondents indicates gaps in implementing policies through Policy-Practice Alignments; Stakeholders Engagement in Policy Implementation, Active Implementation, or Communication of Policies and Ongoing Evaluation of Policy Implementation in selected public sectors within the study area is not expected.

However, as reported at section 4.2.2 in making the policy and supporting documents transparent to the staff of the sectors and stakeholders the evident majority of the respondents agreed that the documents are accessible in sectors. In consistent with this finding case, [16] argued that creating policy documents accessible to the public in many formats.

\subsection{3. $R Q 3$ \& 4: Multiple Regression and Correlation Results Respectively}

i. Influence of Transformational Leadership Styles on the Effectiveness of Implementation of Public Policies

The research result reported that the influence of the transformational leadership style is statistically significant in selected government public sectors in Addis Ababa City Government. The finding consistent with most of results on previous studies reviewed in chapter two. For example, the finding strongly supported by [33] that transformational leadership refers to a process of developing a commitment for the implementations' of strategies, objectives, and mission of an organization to make effective organizational performance.

Moreover, the study finding of [34] also consistent this finding that organizations are more effective and strong if the leaders show their people by example what they want them to do as well as the principles they want to operate under where decisions are shaped by values and principles. The finding also supported by [35] who found that transformational leaders encourage subordinates to put in extra effort and to go beyond what they (subordinates) expected before. Transformational leaders achieve the greatest performance from subordinates since they are able to inspire their subordinates to raise their capabilities for success and develop subordinates innovative problem solving skills.

ii. Influence of Transactional Leadership Styles on the Effectiveness of Implementation of Public Policies

As indicated in theoretical framework of the study, ttransactional leadership theory focused on maintaining the status quo and the primary goal of the followers is to obey the instructions and commands of the leader [36]. Similarly, there are leaders who practice transactional leadership style often and frequently. However, the research result indicated transactional leadership style has not influenced/predicts the effectiveness of the implementation of policies significantly. Thus, those of leaders who use the transactional leadership style could not influence the implementation process of policies significantly. The finding consistent with [36] reviewed at chapter two of this study. He/she strongly suggest the transactional leader is more a manager than a leader, and is highly focused on getting tasks accomplished, providing very clear direction, and overseeing productivity in detail and tends to think inside the box when solving organizational problems. Leaders who used transactional leadership style of the selected public sectors will not significantly contribute the effectiveness of policy implementation process.

iii.Influence of Laissez-Faire Leadership Styles on the Effectiveness of Implementation of Public Policies

As the research result at sub-section reveled laissez-faire leadership style has not influenced the effectiveness of the implementation of policies significantly because sig shows 0.957 which is greater than 0.05 . The finding of this study consistent with [37] that there were no significant relationships between laissez-faire style and performance of an organization. However, there are leaders who exhibited a laissez-faire leadership style in their daily work. Therefore, these leaders have no significant positive influence on the effectiveness of the implementation of policies.

In Summary, leadership has a significant positive influence on the implementation effectiveness of policies [5]. Approved that the policy implementation process needs a strong manager and organization. Organizations need effective managers and employees to achieve their objectives. Organizations cannot succeed without their personnel efforts and commitment. In support, leadership may have a prominent role in some phases of the policy process. Leadership plays an important role in the implementation of reform because it involves two of the most important aspects of reform, change, and people [35]. The findings are consistence with [37] point of view that leadership is viewed as one of the fundamental drivers of organizational success for both now and the future. Organizational success achieved through the willingness and 
active participation leaders and employees. In consistent with the previous study of [37] the results of correlation analysis indicated transformational and transactional leadership styles have positive correlations with Effectiveness of Implementation of Policies. In similar to this finding [37] responsible leadership provides the base line for strategic thinking and by providing vision it directs the organization towards and tries to align the organization with the required change of environment. Then its attention shifts towards the strategy implementation.

\subsubsection{The Influence of Leaders Leadership Style on the Effectiveness of Policy Implementation Process (Summary)}

The study finding assured that the role of a leader is pivotal for the success of an organization. In consistence, [37], support the finding organizations in all sectors are striving to succeed despite the many challenges. Organizational leadership is a critical component in strategy implementation since it coordinates the entire process right from the development of strategies through implementation up to monitoring and evaluating the success as well as failures of the strategy. It therefore provides the 'engine' of strategy implementation in the organization. Thus lack of or failure of leadership in any organization set up is simply disastrous.

It could also infer that, the result of the study specified that transformational leadership style have statistically significance positive influence on policy implementation effectiveness. Both transactional and Laissez-Faire Leadership Style have no statistically significance positive influence on implementation process effectiveness of policies. Surprisingly, Laissez-Faire Leadership Style has statistically insignificant negative influence on policy implementation process. Hence, if organizations exercise transformational leadership style other than transactional and Laissez-Faire Leadership will contribute the effectiveness of policy implementation process. Because, researchers justified the influence leadership style on organization effectiveness through policy implementation.

Moreover, the finding consistent studies like [34] that argued leadership style in an organization is a key factor affecting the success or failure of strategy implementation. A good leadership style guides how staff members relate, work and commit themselves to the organizations. The finding that while the centerpiece of any policy implementation begins from the human factor and it relates to human resource management that challenges the numerous reform and development policy implementation [7]. This study also supported the finding that human factor includes leaders of an organization. However, the result contradicted with that of [37], the successful implementation of public policies depends on externally as well as internally located driving forces, and leadership regarded as the external driving force. Therefore, there is the devotion of this research findings and [37]. It indicates further research that will focus on is leadership external factor that affect policy implementation or internal factor.

\section{Conclusion and Recommendation}

\subsection{Conclusion and Leadership Implication}

This research work designed and scientifically carried out to look at the influence of leaders' leadership style on the effectiveness of policy implementation process in selected public sectors of the city government of Addis Ababa.

Effective public leadership regarded as prerequisite for proper public policy implementation. In summary, from the findings of this study it infer that implementation effectiveness of policies influenced by specific leadership style of leaders. If leaders exhibited transformational leadership more, the Effectiveness of Implementation of Policies can enhance in selected government public sectors in Addis Ababa City Government. Consequently, the study infers that leadership style encompasses a key influence on the effectiveness or failure of policy implementation i.e., an appropriate leadership style leads the organization effective in policy implementation whereas, an inappropriate leadership style guides the organization's failure in policy implementation. Further, if there is lack or failure of leadership in an organization leads to influence the implementation of policies.

More specifically, as findings leaders within the selected government public sectors in Addis Ababa City Government applied transactional leadership style followed by transformational and Laissez-faire leadership styles. The finding concretely implies that within the selected public sectors, there's a variation in using leadership style and therefore the variation leads public sectors to align the policy with the vision, mission and goals of it. The variation in using leadership style calls leaders to lead bureaucrats of public sectors to be committed and competent enough for achieving the goals of the organization.

In terms of effectively implementing public policies, the finding indicates the policy implementation process somewhat effective in applying a number of the symptoms of public policy implementation process effectiveness. It imply that there are gaps or ambiguity in policy implementation process and therefore, the gaps or ambiguity leads ineffective implementation of policies in public sectors of Addis Ababa city government. However, the observation indicates there are gaps in active implementation or communication of policies, aligning policy with practice, ongoing evaluations of the implemented policies. The finding has an implication for those leaders in selected public sectors of Addis Ababa city government implementing public policies in an exceedingly linear way that's why the finding shows positive agreement in mere two of the well-known indicators of policy implementation effectiveness.

This study was observed that the transformational leadership style was found to own significant positive influence/predicts of the effectiveness of the implementation of policies and it'll contribute or influence significantly $(34.7 \%)$ of the effectiveness of policy implementation process which is healthier than the other leadership style. This leadership style also positively and significantly 
correlated with the Effectiveness of Implementation of Policies $(r=0.327$ and $\operatorname{sig}=0.000)$. Thus, it denote that if leaders of the selected public sectors in Addis Ababa city government focused their energies on transformational leadership style (Inspirational Motivation, Idealized Influence, Intellectual Stimulation, and Individual Consideration) in leading the sectors they motivate subordinates of followers to exert extra efforts to achieve the objectives of an organization. In these sense, leaders who have this leadership style helps public sectors to achieve the objectives of policies.

While there is no significant influence of transactional leadership style on the effectiveness of the implementation of policies and it contributes or influence $(9.7 \%)$ of the effectiveness of the policy implementation process. There is a moderate relationship between transactional leadership style and the Effectiveness of Implementation of Policies ( $\mathrm{r}=0.148$ and sig 0.023) However, leaders of the selected public sectors of Addis Ababa city government mostly practiced transactional leadership style. It deduce that the leaders of the selected public sectors negatively reinforced to use transactional leadership. This finding also offer the basic information for leaders of public sectors in Addis Ababa city government, as they indicate that leading followers through transactional leadership style will not influence them to implement policies in effective manner.

In other words, there are not any significant positive influences of laissez-faire leadership style on the effectiveness of the implementation of policies even insignificantly negatively influence the effectiveness of the policy implementation process and it could contribute or influence $(-3 \%)$ of the effectiveness of policy implementation process and the Style contains a negative and insignificant correlation with Effectiveness of Implementation of Policies $(\mathrm{r}=-0.024$, sig $=0.717)$ in Addis Ababa City Government. That's why, there are gaps in effectively implementing public policy indicators like the active implementation of policies, aligning policy with practice, ongoing evaluations of the implemented policies.

Finally, the result of this study demonstrate that there is a visible influence of leaders leadership style on the implementation process effectiveness process of policies in selected public sectors of the city government of Addis Ababa. To end, it is important to stress that policy implementation and leaders leadership style have significance relationship so far.

\subsection{Recommendation}

Study findings showed that in comparing transformational and laissez-faire leadership styles almost all leaders within the study area used transactional leadership style frequently, however; researchers suggest that employing a different approach of leadership in leading followers and achieving policies is crucial within the modern world. Therefore, organizations like charge with leadership capacity building and leadership recruitment and appointment in government public sectors of Addis Ababa City Government better give training in using different leadership approaches to be contextual in using leadership style or helps leaders in identifying the leadership style that has more significance influence on policy implementation process effectively.

The research indicates there are gaps in active implementation/communication of policies, aligning policy with practice, ongoing evaluations of the implemented policies. Hence, policymakers (city government of Addis Ababa people council) and the city government, in general, would be conduct ongoing assessment on the implementation of policies and in stole feedback loop/system.

As the study showed that, transformational leadership style influenced public policy implementation effectiveness over other leadership styles in study area. It's therefore informed leaders of public sectors and others in managerial positions to implement policies effectively they have to make a work condition that supports transformational leadership style in the current context or being contextual in using leadership styles through training of leadership approaches by the professional of leadership.

The study finding contradicted with the finding of Bekker and Heyningen (2011). It indicates management or leadership professionals of the Addis Ababa city government better to research either leadership is external factor that affect policy implementation or internal factor.

This study focused on investigating the influence of three leadership styles and policy implementation stage only in Addis Ababa city government. Thus, it is better to conduct in other study areas with different leadership styles and other stages of policy development i.e., policymaking, policy input, policy output, and policy outcome.

Future research may expand the investigations to search out why public policy implementation process effectiveness associates with a transformational leadership style apart from transactional and Laissez-Faire styles.

\section{References}

[1] Boehnke, K., Bontis, N. Distefano, J., \& Distefano, A. (2003). Transformational Leadership: An Examination of Crossnational Differences and Similarities. Leadership and Organization Development Journal, 24 (1/2), 5-17.

[2] Akinboye, J. (2005). Executive behavior battery. Ibadan: Stirling Horden Publishers.

[3] Fadel, M. (2014). Leadership, Governance and Public Policy Implementation Competencies in the Broader Public Sector. European Journal of Business and Management. Vol. 6, No. 36 .

[4] Swamy, R. \& Nanjundeswaraswamy, S. (2014). Leadership styles. Department of Industrial Engineering and Management. JSS Academy of Technical Education, Bangalore, INDIA. Vol. 7 (2) February (2014).

[5] Rad, A. \& Yarmohammadian, M. (2017). A study of relationship between managers' leadership style and employees' job satisfaction. Leadership in Health Services Vol. 19 No. 2, 2006. 
[6] Bezabih Bekele. (2009). Implementation Challenges of Service Delivery Policy of Ethiopia: Civil Servants' Perspective. Addis Ababa University.

[7] Dereje Terefe. (2016). Assessment of Wereda Policy Implementation Capacity Opportunities and Challenges. The case of selected Wereda administrations in Yeka Sub City, Addis Ababa.

[8] Marume, M., Mutongi, C. \& Madziyire, N. (2016). An Analysis of Public Policy Implementation. IOSR Journal of Business and Management (IOSR-JBM) Volume 18, Issue 4. Ver. I (Apr. 2016), PP 86-93.

[9] Pulzl, H. \& Khandaker, T. (2011). Implementing Public Policy. CRC Press of Taylor \& Francis Group, an informal business. New York.

[10] Anderson, F. and James, E. (2006). Policymaking. (Sixth Ed.) USA: Houghton Mifflin Company.

[11] http://www.businessdictionary.com/definition/transformationa 1-leadership.html.

[12] Kyalo, J., Katuse, P. \& Kiriri, P. (2016). Effect of Organizational Leadership on Strategy Implementation in Kenya's Tourism Industry: Case of Kenya Government Tourism Agencies. The International Journal of Business \& Management.

[13] Khan, R. \& Khandaker, S. (2016). A Critical Insight into Policy Implementation and Implementation Performance. Visio Political Ire Administration Public Policy and Administration 2016, T. 15, Nr. 4/2016, Vol. 15, No 4, P. 537548 .

[14] Chapman, C. (2016). How Public Service Leadership is Studied: An Examination of A Quarter Century Of Scholarship, Public Administration.

[15] Stonemeier, J., Trader, B., Kaloi. L. and Williams, G. (2016). Indicators of Effective Policy Development \& Implementation. School Wide Integrated Framework for Transformation. U.S. Department of Education.

[16] Federal Democratic Republic of Ethiopia. (1995). Constitution.

[17] Federal Republic of Ethiopia Policy Research Center. (2016). Private Manufacturing Industries Role, Challenges, Opportunities and Recommendations. Industry development research department. Addis Ababa Ethiopia.

[18] Ministry of capacity building. (2008). Public sector capacity building program evaluation report. Addis Ababa.

[19] Tesfaye Debela and Zerihun, Duressa. (2014). Leadership Effectiveness in Public Service Organizations of Ethiopia: Perceptions of Leaders in Public Service Organizations. Journal of Law, Policy and Globalization Vol. 26, 2014.

[20] Abdu Abagibe \& Kidanemarian Berhe. (2017). Leadership Training Outcome Assessment. FDRE Meles Zenawi Leadership Academy. Addis Ababa.

[21] Chane Paulos. (2000). Civil Service Reform in Ethiopia: Problems and Prospects. Regional and Local Development Studies (RLDS) Working Paper, Addis Ababa University, Addis Ababa. (p. 57).
[22] Yalew Endaweke. (2012). [Application of Basic Research Principles]. Mega Publishing Enterprise.

[23] Kothari, C. (2004). Research Methodology: Methods and Techniques New Age International.

[24] Yadesa Tollesa. (2010). [Educational and Action Research Methods]. Mega Publishing Enterprise.

[25] Burns, J. (1978). Leadership. New York: Harper \& Row.

[26] Maria, A. \& Renata, S. (2017). Performance and Leadership Style: When Do Leaders and Followers Disagree? Mackenzie Management Review (Rev. de Adm. Mackenzie - RAM), Vol 18 No 2 .

[27] Mothae, L. \& Sindane A. (2008). The strategic and shared leadership between municipal officials and political office bearers in local government: A recipe for good governance and enhanced service delivery. Paper presented at IASIA Annual Conference in Uganda Kampala.

[28] Hair, J., Anderson, R., Tatham, R. \& Black, W. (1995). Multivariate data analysis with readings. 4th edn. PrenticeHall International, Englewood Cliffs, pp. 274.

[29] Kolzow, D. (2014). Leading From Within: Building Organizational Leadership Capacity.

[30] Debela Tezera. (2019). Factors for the Successful Implementation of Policies. Merit Research Journal of Education and Review (ISSN: 2350-2282) Vol. 7 (8) pp. 092095. August 2019. Available online http://meritresearchjournals.org/er/index.htm

[31] Zahari, I. \& Shurbagi, A. (2012). The effect of organizational culture and the relationship between transformational leadership and job satisfaction in petroleum sector of Libya. International Business Research, 5 (9), 89-97.

[32] Iqbal, N., Anwar, S. \& Haider, A. (2015). Effect of Leadership Style on Employee Performance. Arabian Journal of Business and Management Review.

[33] Kingsley, O. and Osahon, J. (2016). Statistical Approach to the Link between Internal Service Quality and Employee Job Satisfaction: A Case Study. American Journal of Applied Mathematics and Statistics. 2016, Vol. 4 No. 6, 178-184.

[34] Namusonge, G. and Koech, M. (2012). The Effect of Leadership Styles on Organizational Performance at State Corporations in Kenya. International Journal of Business and Commerce Vol. 2, No. 1: Sep 2012 [01-12].

[35] Loganathan, R. (2013). The Influence of Leadership Styles on Job Satisfaction at A Cellulose Pulp Mill in Kwazulu-Natal: A Case Study. Durban University of Technology

[36] Saqib, S., Rashid, S., Ikram, S. and Azhar, A. (n.d). The Role of Leadership in Strategy Formulation and Implementation. International Journal of Management \& Organizational Studies VOLUME 1, ISSUE 2.

[37] Bekker, J. and Heyningen, H. (2011). A Strategic Leadership Model for Policy Implementation. University of the Free State South Africa. 